\title{
The sputtering of AlN films on top of on- and off-axis 3C-SiC (111)/Si (111) substrates at various substrate temperatures
}

\author{
A. Iqbal ${ }^{1,2}$, G. Walker ${ }^{1}$, L. Hold ${ }^{1}$, A. Fernandes ${ }^{3}$, P. Tanner ${ }^{1}$, A. Iacopi ${ }^{1}$ and F. Mohd-Yasin ${ }^{1}$ \\ ${ }^{1}$ Queensland Micro- and Nanotechnology Centre, Griffith University, Nathan, 4111, QLD, Australia \\ ${ }^{2}$ Military College of Signals, National University of Science and Technology, Islamabad, Pakistan \\ ${ }^{3}$ Bluglass Ltd., 74 Asquith Street, Silverwater, 2128, NSW, Australia \\ E-mail address of corresponding author:f.mohd-yasin@griffith.edu.au
}

Telephone: +61737358015, Fax: +61737358021

\begin{abstract}
AlN thin films have been sputtered on top of the on-axis and $4^{\circ}$ off-axis 3C-SiC (111)/Si (111) substrates at various substrate temperatures. The grazing angle incident XRD scans show that all films have major peak at (002) plane and minor peaks at (101) and (102) planes. The AlN films are further characterized in terms of the FWHM of the rocking curve, surface morphology and deposition rate. We observed that the increasing substrate temperature improve the crystal quality of the AlN (002) films, but it has minimal impact on the surface roughness and deposition rate. We also extracted the values for the bi-axial stress, the grain size and the piezoelectric coefficient. Overall, the off-axis 3C-SiC/Si (111) substrates provide a better template for the sputtering of AIN (002) films in term of better crystal quality, lower surface roughness and lower bi-axial stress.
\end{abstract}

Keywords: Physical vapour deposition processes; Polycrystalline deposition; X-ray diffraction; Aluminum Nitride; Silicon carbide

\section{Introduction}

Aluminum nitride (AlN) has excellent electrical properties such as high electrical resistivity $\left(10^{15} \Omega . \mathrm{cm}\right)$, high thermal conductivity $\left(3.3 \mathrm{WK}^{-1} \mathrm{~cm}^{-1}\right)$ and wide bandgap $(6.2 \mathrm{eV})$ [1-3], which makes it a potential candidate for power electronics applications. AlN is also used in RF MEMS because of a high acoustic velocity (12,000 m/s) [4]. Another significant use of the AlN thin-films is to fabricate piezoelectric sensors and actuators [5]. The 
piezoelectric properties of AlN strongly depend on the crystallographic orientation. The caxis oriented AlN thin films are preferred for the piezoelectric applications because of its high $d_{33}(5.0961 \mathrm{pm} / \mathrm{V})$ [6,7]. Furthermore, the coupling coefficient of the AlN thin filmbased devices is closely related to the c-axis orientation of the deposited film [8].

In order to yield a highly c-axis AlN films, numerous research groups investigated the influence of deposition parameters on the crystal orientation of the deposited films. The process parameters such as the sputtering power, the gas ratio, the process pressure, and the substrate temperature directly affect the crystal quality and texture of the deposited films [9]. The substrate temperature largely influences the kinetic energy available to the adatoms on the surface of the deposited films. This energy increases proportionally with an increase in the substrate temperature, which helps in depositing the highly c-axis oriented films $[10,11]$. However, after the optimum temperature range, a further increase in the substrate temperature increases the thermal stresses in the film because of the coefficient of thermal expansion (CTE) difference when cooling down to room temperature. In addition, there are many impurities that are absorbed through the surface of the film at such high temperature [8]. In turn, both factors decrease the film's crystal quality.

Several published works that deposited the AlN film on top of the Si substrates and varied the substrate temperature are mentioned herein. In one work, Barshilia et al. [12] deposited a highly c-axis oriented AlN film starting at $100{ }^{\circ} \mathrm{C}$. When the substrate temperature was increased from 200 to $350{ }^{\circ} \mathrm{C}$, they observed the decrease of the (002) diffraction peaks, whereas other diffraction peaks i.e. (100), (101) and (102) started to appear. In another work, Jin et al. [10] studied the influence of the substrate temperature on the AIN films as the temperature increased from 60 to $520{ }^{\circ} \mathrm{C}$. They noticed significant effects on the crystal orientation, the surface morphology and the deposition rate, and reported the optimized substrate temperature of $430{ }^{\circ} \mathrm{C}$ for the c-axis AlN films. Kar et al. [13] studied the 
correlation between the electrical properties and the surface morphology of the AlN films between the substrate temperature of 100 to $400{ }^{\circ} \mathrm{C}$. They remarked that the highly c-axis films with highest $d_{33}$ constant were deposited between the substrate temperatures of 200 to $300{ }^{\circ} \mathrm{C}$.

There are also other groups that reported the effect of the substrate temperature on the quality of the AlN films being sputtered on top of the non-Si substrates. In one such work, Chiu et al. [6] deposited the AlN (002) film on top of the Platinum (Pt) electrode to make the thin film bulk acoustic resonator. The substrate temperature was varied between 250 to 450 ${ }^{\circ} \mathrm{C}$. The minimum FWHM of rocking curve value of $2.7^{\circ}$ was obtained at $400{ }^{\circ} \mathrm{C}$. They explained that the high adatom mobility increased its surface diffusion length, which then helped the adatoms to migrate to the proper site of the (002) plane. In another work, Kuang et al. [7] investigated the influences of substrate temperature between the range of 30 to $700{ }^{\circ} \mathrm{C}$ to the chemical composition, crystalline structure and surface morphology of the AlN (002) films on top of the sapphire substrate. They concluded that the substrate temperature of 300 ${ }^{\circ} \mathrm{C}$ assisted in producing the highly c-axis films. In one of the latest reported works, Wang et al. [14] deposited the AlN films on top of the glass substrates and increased the substrate temperature up to $500{ }^{\circ} \mathrm{C}$. They found that the highest quality films were produced at $300{ }^{\circ} \mathrm{C}$, in combination with the negative substrate biasing. In another work, Yang et al. [15] deposited the AlN film on top of the Molybdenum substrate between 20 to $600{ }^{\circ} \mathrm{C}$, and found $400{ }^{\circ} \mathrm{C}$ to be the optimized substrate temperature.

As described in the previous two paragraphs, a number of articles reported the influence of the substrate temperature on the quality of the sputtered AlN (002) thin film. The majority of these works deposited these films on top of the Si substrates for the ease of CMOS integration. However, the $47 \%$ difference in term of the CTE between AIN $\left(4.3 \times 10^{-6}\right.$ $\left.\mathrm{K}^{-1}\right)$ and Si $\left(2.6 \times 10^{-6} \mathrm{~K}^{-1}\right)$ [16] generates thermal stresses, disruptions and crystal defects 
when this compound structure is being cooled down from the high substrate temperature. One practical solution was to employ the 3C-SiC buffer layer to reduce the CTE difference to $18 \%$, which was done by our group. In our previous work [17], we investigated the influence of Nitrogen $\left(\mathrm{N}_{2}\right)$ concentration on the crystal quality of the c-axis oriented AlN thin film on top of a Si (111) substrate with a 3C-SiC (111) buffer layer. However, we experienced arching issue with the DC sputtering system. Therefore in this latest work, we employed a pulsed DC sputtering technique to solve the problem.

From the literature review, the $3 \mathrm{C}$-SiC layer being grown on top of the on-axis $\mathrm{Si}$ substrate has structural defects because of the $20 \%$ lattice mismatch and the $8 \%$ CTE difference [18]. Therefore, several groups grew the 3C-SiC layer on top of the off-axis $\mathrm{Si}$ substrates to mitigate the problem. In one of the earliest works, Powell et al. [19] observed that all traces of the anti-phase disorder were eliminated in the 3C-SiC films that were grown on top of the off-axis substrates, whereas all of the as-grown on-axis films exhibited an irregular shaped line. In another work that was produced in our research centre, Wang et al. [20] reported that the 3C-SiC film grown on top of the $4^{\circ}$ off-axis Si substrates had the smaller surface roughness, narrower FWHM peak and smaller bow magnitude compared to the ones that were grown on top of the on-axis Si substrates. There was also an Italian group that investigated this issue. Severino et al. [21] deposited 3C-SiC (111) film on top of $3^{\circ}$ offaxis Si substrate. They observed that the stacking fault density decreased dramatically compared to the films grown on top of the on-axis Si (111) substrates. They concluded that the off-axis Si substrate helps in the suppression of the double positioning boundaries. A year later, the same group grew 3C-SiC films on top of 6 inch (111) $4^{\circ}$ off-axis Si wafers, which was tilted towards the (110) plane. They reported an extremely flat surface of SiC film that can be potentially used for electrical and mechanical device applications [22]. 
The major contribution of this paper is the investigation on the influence of the onaxis and off-axis 3C-SiC(111) / Si (111) substrates towards depositing AlN (002) films. Based on the previous works that are described in the previous paragraph, the expectation is for the off-axis substrate to provide a better template for the sputtering of the film. In addition, the influence of the substrate temperature towards the quality of the AlN film will be examined as well. The rest of this paper is as follows. Section 2 discusses the experimental details, while section 3 tabulates the empirical data with the analysis of the trends. Section 4 concludes the paper.

\section{Experimental Details:}

Prior to the AlN film deposition, the $80 \mathrm{~nm}$ thick 3C-SiC (111) film was grown on top of the $150 \mathrm{~mm}$ Si (111) wafers in an epitaxial reactor (SPT Microtechnologies, San Jose, CA, USA). This work was performed by another group in our research centre i.e. Wang et al. [20]. Therefore, the processing details and the characterization of the 3C-SiC films were already reported in that paper and will not be repeated here.

For this experiment, we have randomly selected two 3C-SiC/Si wafers from the inventory. The first one, referred herein as an on-axis substrate has an off-cut angle of $0.5^{\circ}$, while the other one, referred herein as an off-axis substrate has an off-cut angle of $3.5 \pm 0.5^{\circ}$ towards (110) plane. Artieda et al. [23] reported that the surface roughness of the substrate influenced the quality of the c-axis AlN film on top of it. Therefore, we measured this parameter for both wafers using the following microscope (NX20 Atomic Force Microscopy (AFM), Park Systems, Suwon, Korea). Fig 1(a) and Fig 1(b) shows the images of this AFM scan. The on- and off-axis SiC/Si wafers have the surface roughness (in rms) of $2.386 \mathrm{~nm}$ and 
$0.93 \mathrm{~nm}$, respectively. It is clear from both figures that the off-axis surface is more dense and uniform with lower defect density as compared to the on-axis surface.

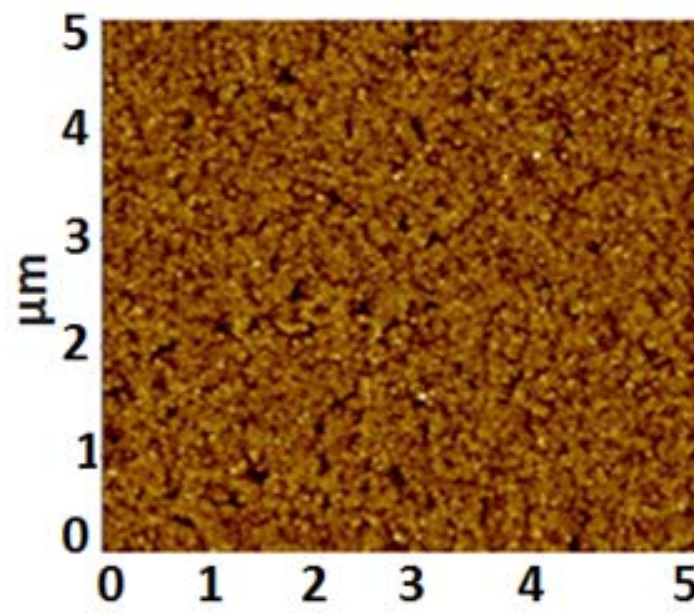

(a)

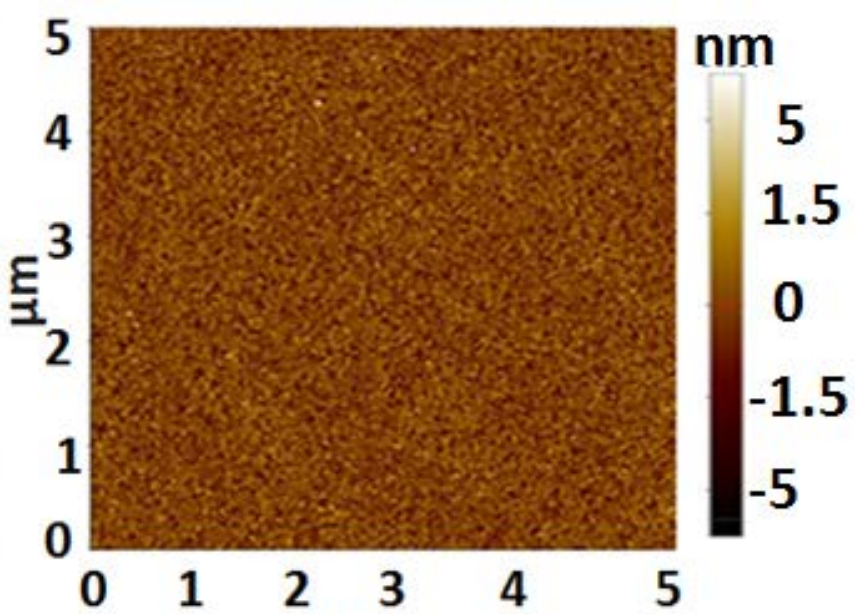

(b)

Fig. 1 (a) AFM image of the on-axis 3C-SiC/Si surface

Fig. 1 (b) AFM image of the off-axis 3C-SiC/Si surface

Initially, the 3C-SiC/Si wafers were cut to the size of $15 \mathrm{~mm}$ by $15 \mathrm{~mm}$ samples using a Disco dicing saw (Disco Corp., Tokyo, Japan). The samples were then cleaned via a standard piranha cleaning process to remove the organic substances, followed by submersion in a diluted $1 \% \mathrm{HF}$ acid for 5 min to remove the oxides.

The pulsed DC sputtering of the AlN thin films on top of the 3C-SiC-on-Si (111) substrates was performed using a magnetron sputtering system (Gamma 1000, Surrey Nano Systems, Newhaven, UK) at the sputtering power of $1800 \mathrm{~W}$. This value has been determined to be the optimized power from previous experiment [17]. The pulsed DC power supply (Pinnacle Plus, Advanced energy, Fort Collins, USA) was utilized at $250 \mathrm{kHz}$ with the time off of $0.4 \mu$ s to avoid the electrical arcing. The samples are inserted into the sputtering system in two stages. The first is a turbo-pumped load lock, and the second is a deposition chamber. 
In the first stage, the samples were loaded into a susceptor (sample carrier) and heated in the load lock to $200{ }^{\circ} \mathrm{C}$ with an infrared (IR) heater for 3 min to remove the moisture after the pressure had reached $10^{-6}$ Torr. In the second stage, the susceptor was then loaded into the deposition chamber through the isolating gate valve for the reactive AlN sputtering.

The deposition chamber is highly vacuumed with an ultimate base pressure of $10^{-9}$ Torr. The chamber consists of a cryogenic pump, $4 \times 4$ inch sputtering targets, shutters, gas feeds and substrate holder (or susceptor). This susceptor could be heated and electrically biased. The choices of sputtering power that can be selected are DC, pulsed DC or RF. From the previous experiment [17], the reactive gas i.e. $\mathrm{N}_{2}$ formed a coating (insulator) on the target that would lead to the arcing and instabilities using the DC power. Therefore, in this experiment the pulsed DC power was employed. The pulsed DC voltage was applied between the target and substrate to create the plasma state in the chamber. The negative DC voltage was applied to the $\mathrm{Al}$ target which served as the cathode, while the positive DC voltage was applied to the susceptor which acted as the anode. The chemically inert Argon (Ar) gases were fed into the deposition chamber and get ionised. The negative ions of Ar accelerated to the positively-charged susceptor, while its positive ions accelerated and collided with the negatively-charged Al target. As a result of the collision, some Al's atoms and molecules were ejected out from the target's surface and get ionized. In the meantime, the $\mathrm{N}_{2}$ gas was fed to the chamber. Under the pre-determined 'poison' condition, the $\mathrm{N}_{2}$ ions reacted with the negatively-charged $\mathrm{Al}$ atoms and molecules to form AlN. The negatively-charged AIN molecules were attracted towards the positively-charged susceptor. They eventually changed state from plasma to solid on the surface of the susceptor. The structure of the AlN crystal is largely dependent on the available kinetic energies on this surface.

We employed an $\mathrm{Al}$ target of $100 \mathrm{~mm}$ in diameter with $99.999 \%$ purity. The target to the substrate distance was set to $20 \mathrm{~cm}$, which was a default value for the equipment. The in- 
situ RF reactive ion etching was carried out on the SiC surface on top of the susceptor to aid adhesion of the AlN film, as what was performed by [24]. All the sputtering was performed at the process pressure of 2 mTorr. This was the lowest pressure that could be achieved without destabilizing the power supply. We set the $\mathrm{N}_{2} / \mathrm{Ar}$ ratio of $58 \%$ at the total flow rate of 60 sccm. This ratio was determined as the optimized "poison" condition from the hysteresis that was explained in Figure 1 of our previous article [25]. The substrate temperature was increased from 250 to $450{ }^{\circ} \mathrm{C}$ in the steps of $50{ }^{\circ} \mathrm{C}$. The deposition lasted for 44 minutes, and resulting in the AlN thicknesses between 646 to $686 \mathrm{~nm}$.

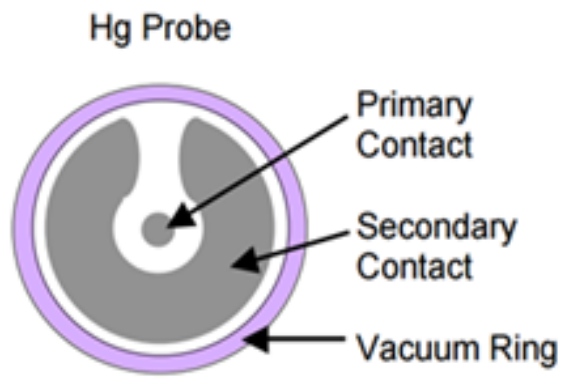

(a)

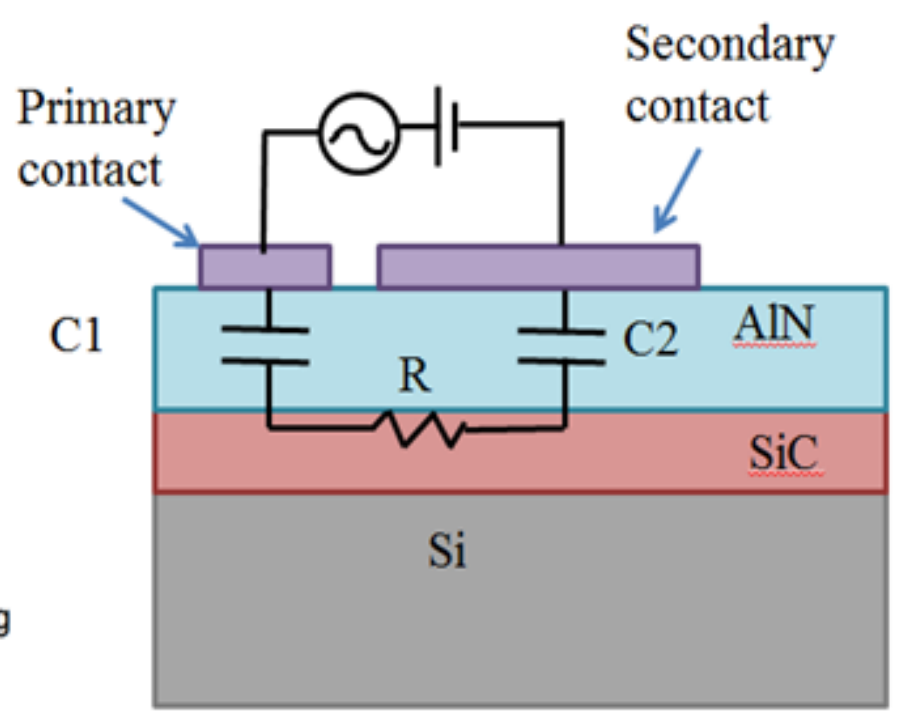

(b)

Fig. 2 (a) The top-view of the head of the probe

Fig. 2 (b) The schematic of capacitance measurement in reference to the AlN/SiC/Si structure. There is no electrical connection between the $\mathrm{Si}$ and $\mathrm{SiC}$ layer. This is because the p-type Si and n-type SiC are reversed-biased.

After the sputtering and the characterizations of the AlN films, we selected one of the best samples and extracted its piezoelectric coefficient $\left(\mathrm{d}_{33}\right)$ value by employing the capacitance-voltage $(\mathrm{C}-\mathrm{V})$ measurement. This measurement was performed using the 
mercury (Hg) probe (Materials Development Corporation, Chatsworth, CA, USA). The topview of the head of the probe is shown in Fig. 2 (a). It consists of an outer vacuum ring, and two Hg contacts. The area of the primary contact is much smaller compared to the secondary contact. The schematic of the capacitance measurement is shown in Fig. 2 (b). The mercury probe is connected in dual front contact mode to the surface of the AlN film. The AlN film is an insulator, which acts as a dielectric while the Hg contacts act as a parallel plate capacitor. The electric field develops across the dielectric AlN when the electric potential is applied on the contacts as shown by $\mathrm{C} 1$ and $\mathrm{C} 2$. The value of $\mathrm{C} 1$ is smaller than $\mathrm{C} 2$ because $\mathrm{C} 1$ has a smaller electrode area. The net capacitance is approximately equal to the value of C1 because both capacitors are connected in series, and hence, the smaller capacitor dominates. The value of the series resistance (R) across the $\mathrm{SiC}$ film is small and therefore is ignored. In other word, we assume a short connection between the SiC layer to the secondary Hg contact in Fig. 2 (b). Therefore, we have a parallel plate capacitor configuration that consists of the primary Hg contact/AlN/SiC (secondary Hg contact) structure. When a DC voltage of -20 to $+20 \mathrm{~V}$ in an increment of $5 \mathrm{~V}$ was applied, the thickness of the AlN piezoelectric layer contracted or expanded, accordingly. The capacitance value can be calculated as follows. Given that the AlN relative dielectric constant $=9.5$, thickness $=657 \mathrm{~nm}$, and area $=4.8 \times 10^{-7}$ $\mathrm{m}^{2}$, the value of the capacitance $\left(\mathrm{C}_{0}\right)$ is equal to $84.75 \times 10^{-12} \mathrm{~F}$ at zero DC bias. The change in the capacitance value $\left(C_{V}\right)$ can be calculated using the capacitance parallel plate formula [26, 27].

$\mathrm{C}_{\mathrm{V}}=\mathrm{C}_{\mathrm{o}}\left(\left(1-\left(\frac{\Delta \mathrm{A}}{\mathrm{A}}\right)\right) /\left(1+\left(\frac{\Delta \mathrm{d}}{\mathrm{d}}\right)\right)\right.$

where both the vertical extension of the AlN material $\Delta \mathrm{d}$, and the variation in area $\Delta \mathrm{A}$ are correlated with the magnitudes of both the longitudinal $d_{33}$ and the transverse $d_{31}$ charge constants as follows [28]: 
$\Delta \mathrm{d}=\mathrm{V}\left|\mathrm{d}_{33}\right|$

$\Delta \mathrm{A}=\frac{\mathrm{V}\left|\mathrm{d}_{31}\right| \mathrm{A}}{\mathrm{d}}$

Moreover, the magnitude of the $d_{33}$ coefficient is about twice the value of $d_{31}$ [28]; therefore,

$\left|d_{33}\right|=2\left|d_{31}\right|$

Solving for $\Delta \mathrm{d}$, we get equation 5 :

$\Delta \mathrm{d}=\mathrm{d}\left(\frac{1-\mathrm{C}_{\mathrm{r}}}{0.5+\mathrm{C}_{\mathrm{r}}}\right)$

where $\mathrm{C}_{\mathrm{r}}$ is the ratio between $\mathrm{Cv}_{\mathrm{v}}$ and $\mathrm{C}_{\mathrm{o}}$.

In summary, the deposited AlN films were characterized by the following parameters (the names of equipment): grazing angle incident X-ray diffraction $\theta-2 \theta$ scan (D8 Advance XRD, Bruker, Billerica, MA, USA), omega scan rocking curve (Empyrean XRD, Almelo, The Netherlands), deposition rate (Nanospec AFT 210, Nanometrics, Milpitas, CA, USA), surface roughness (NX20 AFM, Park Systems, Suwon, Korea), cross sectional SEM (Raith150 TWO, Dortmund, Germany) and C-V measurement (Mercury probes (Materials Development Corporation, Chatsworth, CA, USA)) is connected to the C-V plotter ( Agilent 4284A LCR Meter, Santa Clara, California)). 


\section{Results and Discussions:}

Table I. Characterization results for the AlN films

\begin{tabular}{|c|c|c|c|c|c|c|c|c|c|c|c|}
\hline $\begin{array}{c}\text { Type of } \\
\text { substrate }\end{array}$ & $\begin{array}{c}\text { Sample } \\
\text { ID }\end{array}$ & $\begin{array}{c}\text { Substrate } \\
\text { temperature } \\
\left({ }^{\mathrm{O}} \mathrm{C}\right)\end{array}$ & $\begin{array}{c}<002> \\
\text { peak } \\
\text { position } \\
\left({ }^{\circ}\right)^{*}\end{array}$ & $\begin{array}{c}\text { FWHM } \\
\text { of }<002> \\
\text { diffraction } \\
\text { peak } \\
\left({ }^{\mathrm{O}}\right)\end{array}$ & $\begin{array}{c}\text { FWHM } \\
\text { of } \\
\text { rocking } \\
\text { curve } \\
\left({ }^{\circ}\right)\end{array}$ & $\begin{array}{c}\text { Percentage } \\
\text { of }<002> \\
\text { area } \\
(\%)^{* *}\end{array}$ & $\begin{array}{c}\text { Grain } \\
\text { size } \\
(\mathrm{nm})\end{array}$ & $\begin{array}{c}\text { Surface } \\
\text { roughness } \\
(\mathrm{nm})\end{array}$ & $\begin{array}{c}\text { Biaxial } \\
\text { stress } \\
(\mathrm{GPa})\end{array}$ & $\begin{array}{c}\text { Thickness } \\
\text { (nm) }\end{array}$ & $\begin{array}{l}\text { Deposition } \\
\text { rate } \\
\text { (nm/min) }\end{array}$ \\
\hline \multirow{5}{*}{$\begin{array}{c}\text { On-axis } \\
\text { 3C-SiC } \\
(111) / \mathrm{Si} \\
(111)\end{array}$} & Y1 & 250 & 36.18 & 0.30 & 3.84 & 77.3 & 29.11 & 3.46 & 2.906 & 665 & 15.1 \\
\hline & Y2 & 300 & 36.183 & 0.32 & 3.71 & 78.3 & 27.29 & 3.82 & 2.905 & 648 & 14.6 \\
\hline & Y3 & 350 & 36.16 & 0.29 & 3.47 & 97 & 30.11 & 3.99 & 2.47 & 657 & 14.8 \\
\hline & Y4 & 400 & 36.17 & 0.276 & 2.58 & 99 & 31.63 & 3.35 & 2.69 & 678 & 15.4 \\
\hline & Y5 & 450 & 36.19 & 0.295 & 3.04 & 78.3 & 30 & 3.86 & 3.13 & 680 & 15.3 \\
\hline \multirow{5}{*}{$\begin{array}{c}4^{\circ} \text { off-axis } \\
\text { 3C-SiC } \\
(111) / \mathrm{Si} \\
(111)\end{array}$} & $\mathrm{Z1}$ & 250 & 36.15 & 0.31 & 2.78 & 93.25 & 28.16 & 2.63 & 2.26 & 665 & 15.1 \\
\hline & $\mathrm{Z} 2$ & 300 & 36.19 & 0.31 & 2.75 & 90.5 & 28.16 & 2.92 & 3.13 & 648 & 14.6 \\
\hline & Z3 & 350 & 36.15 & 0.32 & 2.34 & 95 & 27.29 & 2.65 & 2.26 & 657 & 14.8 \\
\hline & $\mathrm{Z4}$ & 400 & 36.13 & 0.33 & 2.6 & 100 & 26.46 & 2.38 & 1.824 & 678 & 15.4 \\
\hline & $\mathrm{Z} 5$ & 450 & 36.16 & 0.31 & 1.91 & 100 & 28.16 & 2.82 & 2.47 & 680 & 15.3 \\
\hline
\end{tabular}

*The XRD peaks can be assigned to wurtzite $<002>$ AlN. The $2 \theta$ peak position for powdered AlN is $36.04^{\circ}$ from JCPDS card \# 01-070-2545 [29].

***Percentage of $<002>$ is calculated by measuring the area under curve for all AlN orientations in the XRD spectra.

Table I summarizes the characterization results for all samples. The characterized parameters are the (002) peak position, the FWHM of (002) diffraction peak, the FWHM of rocking curve, the percentage of (002) area under the curve, the grain size, the surface roughness, the bi-axial stress, the thickness and the deposition rate. The data are divided into two categories. Samples Y1 to Y5 correspond to AlN films on top of the on-axis 3C/Si substrates, while samples Z1 to Z5 correspond to the AlN films on top of the off-axis 3C/Si substrates. Within both categories, the substrate temperature was varied from 250 to $450{ }^{0} \mathrm{C}$. The subsequent paragraphs discuss the influence of the substrate temperature towards the structural and morphological properties of the sputtered AlN films. We also compare the properties on the films that were sputtered on top of the on-axis and off-axis 3C-SiC/Si substrates.

Figure 3 (a) shows the grazing angle x-ray diffraction (GIXRD) scan for the samples on top of the on-axis 3C-SiC/Si substrates at various substrate temperatures. We employed D8 Advance XRD (Bruker, Billerica, MA, USA) for this purpose. GIXRD measurement was 
used due to the lower thickness of AlN films compared to the substrates. It had the following parameters. The voltage and the current used for all measurements were $40 \mathrm{kV}$ and $40 \mathrm{~mA}$, respectively. The $2 \theta$ range was between 20 to 60 degrees, and the glancing angle was $1^{\circ}$. The step size was $0.04^{\circ}$, and the time per step was 0.9999 s. As can be seen from Figure 3(a), the major diffraction peak is observed around $36.2^{\circ}$ in all samples, depicting to the (002) orientation [29]. The precise values of the (002) peak positions at different substrate temperatures are recorded in Table I. The other minor diffraction peaks can be seen at $38^{\circ}$ and $50^{\circ}$, depicting to (101) and (102) orientations, respectively [29]. The percentage of (002) to other AlN crystal orientations is calculated between 77 to $99 \%$ for all samples by measuring the area under the curve. We also extracted the FWHM of the (002) diffraction peak values. We employed Gaussian fitting because of better curve fitting for all the curves compared to Lorentz fitting [30]. The FWHM of diffraction peak parameter reveals that the (002) plane in the film improves with the increasing substrate temperature from 250 to $400{ }^{\circ} \mathrm{C}$, before degrades at $450{ }^{\circ} \mathrm{C}$. This observation is supported by another parameter i.e. the percentage of the (002) area under the curve.

In order to assess the crystal quality, the AlN films were characterized by the omega rocking curve measurements using Empyrean XRD (Almelo, The Netherlands). It used monochromatized $\mathrm{Cu} \mathrm{Ka} \alpha^{1}$ beam with $\lambda=1.5405980 \AA$ and a fixed anti-scatter slit with PIXcel-3D detector. The detector was used in the open mode. The voltage and the current used for all measurements were $45 \mathrm{kV}$ and $40 \mathrm{~mA}$, respectively. The step size was $0.01^{\circ}$, and the time per step was $0.1 \mathrm{~s}$. Figure 3 (b) shows the rocking curve of the (002) peak for the AlN samples on top of the on-axis 3C-SiC/Si substrates. The FWHM of the rocking curve values are recorded in Table I. The value consistently decreases with the increasing substrate temperature that starts at $250{ }^{\circ} \mathrm{C}$. The smallest recorded value of $2.58^{\circ}$ was obtained for sample Y4 at $400{ }^{\circ} \mathrm{C}$, before it increased back to $3.04^{0}$ at $450{ }^{\circ} \mathrm{C}$ for sample Y5. It is safe to 
assume that the optimized substrate temperature is therefore $400{ }^{0} \mathrm{C}$. This trend is in agreement with the literature. In fact, Chiu et al. [6] and Jin et al. [10] found the same optimized substrate temperature for their AlN films. The explanation being given is that after $400{ }^{0} \mathrm{C}$, the crystal structure deteriorates due to the increased thermal stress due to the bigger CTE differences between AIN film and its substrate. The other reason is due to the difusion of impurities into the surface of the AlN film at such high temperature.

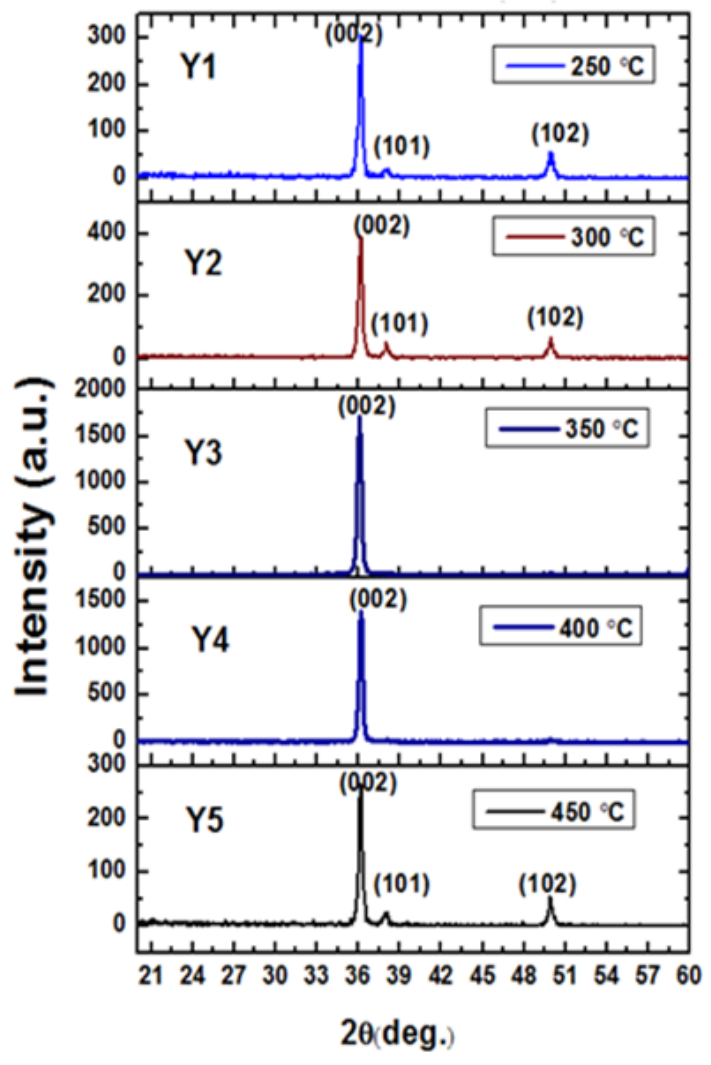

(a)

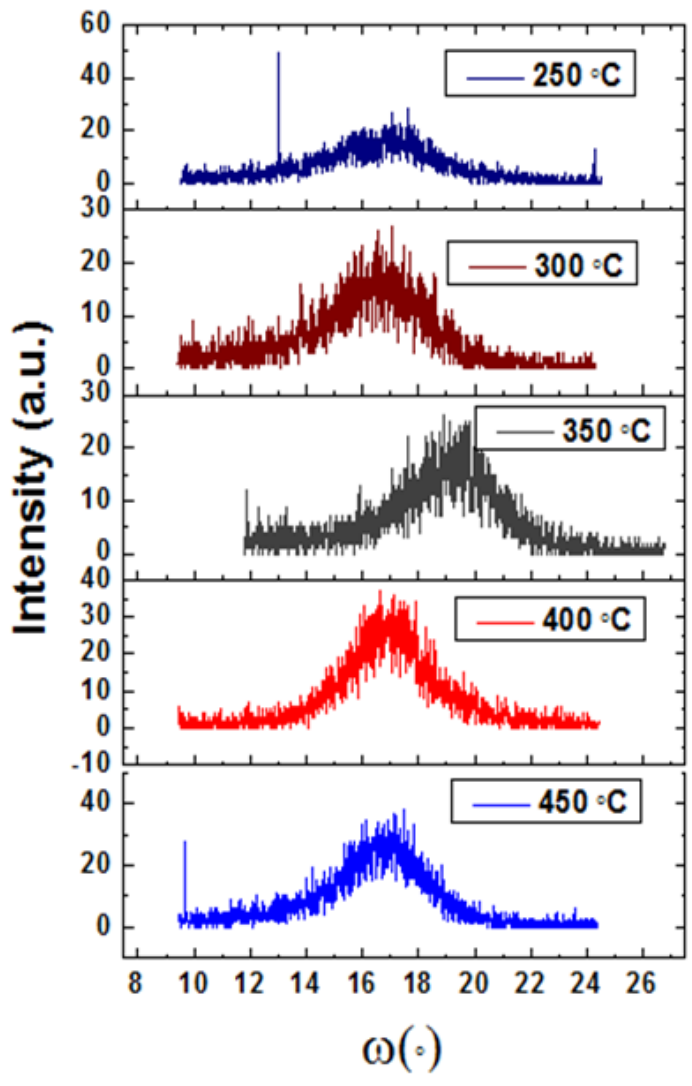

(b)

Fig. 3 (a) GIXRD spectra of AlN films on top of the on-axis 3C-SiC/Si substrates at various substrate temperatures

Fig. 3 (b) Rocking curve of AlN (002) films on top of the on-axis 3C-SiC/Si substrates at various substrate temperatures 


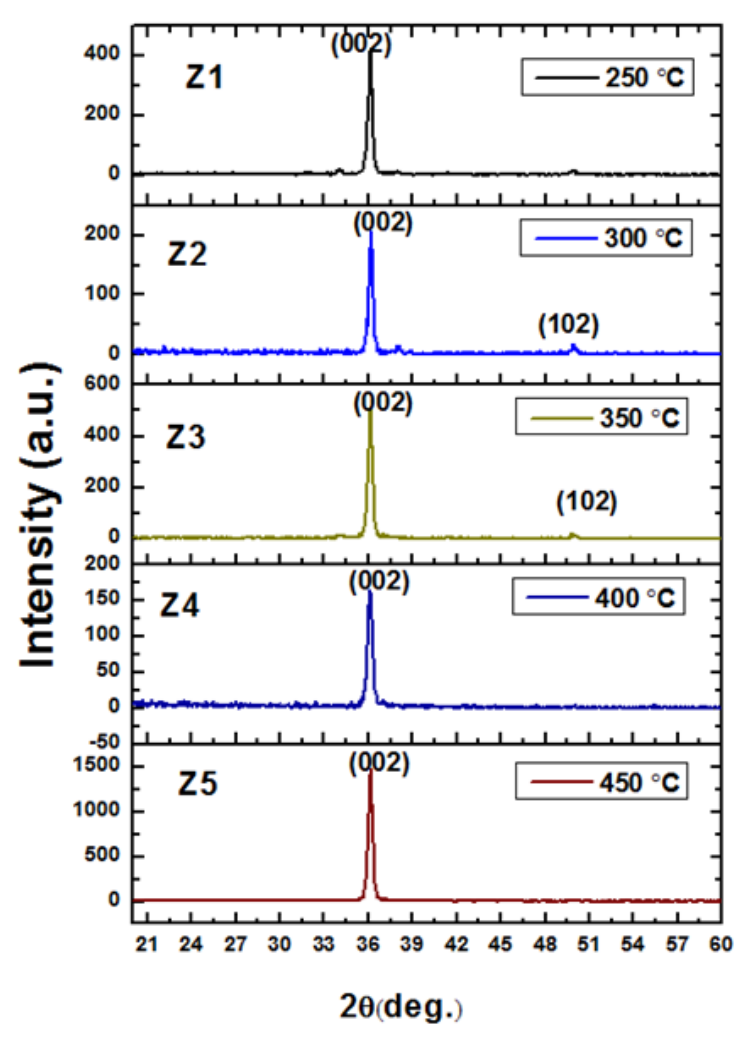

(a)

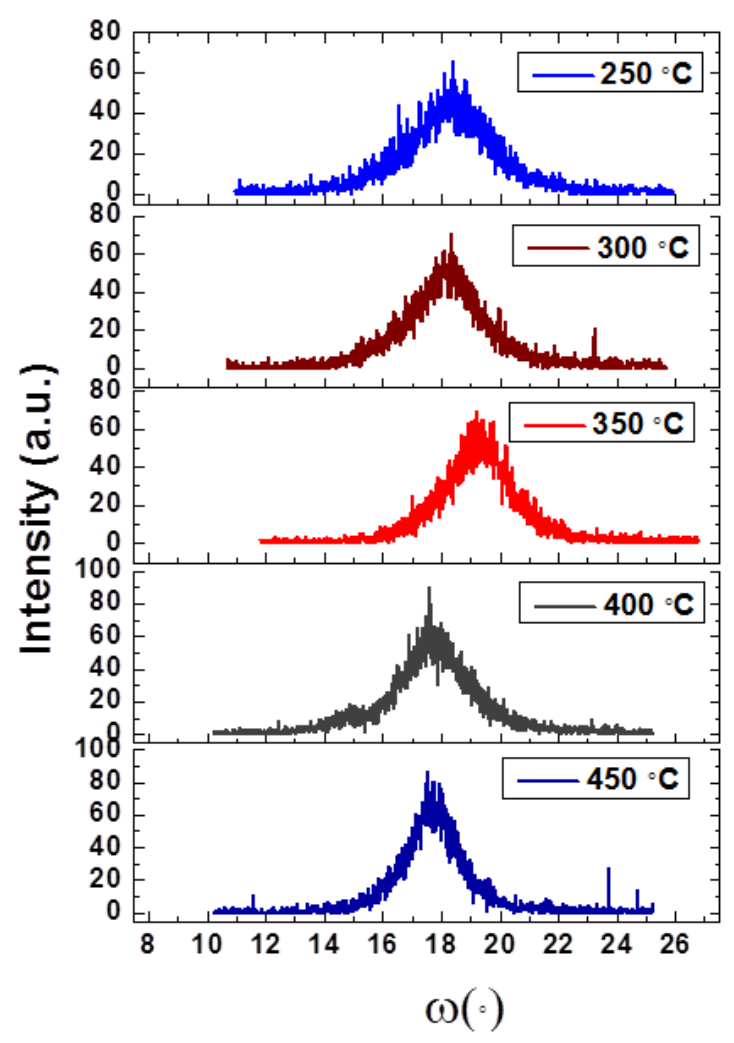

(b)

Fig. 4 (a) GIXRD spectra of AlN films on top of the off-axis 3C-SiC/Si substrates at various substrate temperatures

Fig. 4 (b) Rocking curve of AlN (002) films on top of the off-axis 3C-SiC/Si substrates at various substrate temperatures

Figure 4 (a) shows the GIXRD spectra of the AlN films on top of the off-axis 3C$\mathrm{SiC} / \mathrm{Si}$ substrates at various substrate temperatures. Table I records the data. The major diffraction peak is observed around $2 \theta$ angle of $36.2^{\circ}$ depicting to the (002) orientation [29]. The percentage of (002) to other AlN crystal orientations is calculated between 90 to $100 \%$ for all samples. Figure 4 (b) shows the rocking curve of the (002) peak for the AlN samples on top of the off-axis 3C-SiC/Si substrates. The FHWM of the rocking curve values are recorded in Table I. The trend is very clear. The crystal quality improves with the increased 
substrate temperature and did not deteriorate at $450{ }^{\circ} \mathrm{C}$. It seems that the optimized substrate temperature had not been reached for the samples on top of the off-axis substrates.

We further combed the literature to find out the optimized substrate temperature for the sputtering of the AlN films on a variety of substrates and sputtering equipment. Even though the majority of the published articles reported the range between 300 to $400{ }^{\circ} \mathrm{C}$, there are works that reported much higher values. For example, Medjani et al. [31] deposited the AlN films on top of the Si (100) substrates using RF magnetron sputtering. They reported the optimized substrate temperature of $800{ }^{0} \mathrm{C}$ with the substrate bias voltage of $0 \mathrm{~V}$ to produce the highly c-axis films. In another work, Tungasmita et al. [32] sputtered the AlN films on top of the $6 \mathrm{H}-\mathrm{SiC}$ substrates using $\mathrm{DC}$ magnetron sputtering. They used a commercial substrate from CREE Inc. (Durham, North Carolina, USA), which was $3.5^{0}$ off-axis. Their substrate needed to be heated to $1000{ }^{0} \mathrm{C}$ to achieve the highly c-axis AlN film. In one of the latest reported works, Kumada et al. [33] studied the effect of varying the substrate temperature between 550 to $650{ }^{\circ} \mathrm{C}$ for the deposition of the AlN film on top of the sapphire substrate. Their article provided the flow chart to documents the impact of increasing the substrate temperature to the quality of their deposited films. Based on these three works [31][33], it is very clear that the optimized substrate temperature could be far higher than $450{ }^{0} \mathrm{C}$. Therefore, we are convinced that the optimized value has not been reached for the sputtering of AlN films on top of the off-axis 3C-SiC/Si (111) substrates in this experiment.

After establishing the fact that the AlN films being sputtered on top of the on-axis and off-axis substrates have different optimized substrate temperatures, we compared their crystal qualities. The primary data that are used to make this judgement is the FWHM of the rocking curve values in Table I. It is very clear that the values for the films on top of the off-axis substrates are much smaller, the lowest being $1.91^{0}$ for sample $\mathrm{Z} 5$ at the substrate temperature of $450{ }^{0} \mathrm{C}$. This observation indicates a relationship between the crystal quality of the AIN 
film and the characteristics of its substrate, which has been reported in the literature. In particular for this experiment, since the lattice mismatch and the CTE are similar for the onaxis and the off-axis substrates, the quality of other parameters such as the surface morphology could have significant role [23].

We calculate the grain sizes of all the samples from XRD data using the Scherrer's equation [34]. The values are provided in Table I. The average grain sizes are $29.63 \mathrm{~nm}$ and $27.65 \mathrm{~nm}$ for the films on top of the on-axis and off-axis substrates, respectively. Therefore, there is not much difference in term of the values of this parameter for the films of both substrates. Similar range of grain size was reported by Medjani et al. [31]. The other question is whether there is a noticeable trend between the grain size and the substrate temperature. Many previous works reported that the grain size of the AlN films increases with elevated substrate temperature. The common explanation is due the coalescence of these grains at higher temperature. However, we could not arrive at that conclusion in this paper because of two major reasons. First, there is an inconsistent trend being observed on the films of both substrates. For the samples on the on-axis substrates, the grain size goes down from 250 to $350{ }^{\circ} \mathrm{C}$, then goes up at $350{ }^{\circ} \mathrm{C}$, and goes down again from 400 to $450{ }^{\circ} \mathrm{C}$. For the samples on the off-axis substrates, the grain size goes down from 300 to $400{ }^{0} \mathrm{C}$, then goes up again at $450{ }^{0} \mathrm{C}$. The second reason is due to the small differences between the largest and smallest grain sizes. These differences are only $16 \%$ and $6.4 \%$ for the films on top of the on- and offaxis substrates, respectively. In addition, the values of the standard deviation have been calculated. Their values are 1.59 and $0.76 \mathrm{~nm}$ for the samples on top of the on- and off-axis samples, respectively. Based on these two reasons, we conclude that the grains size has minimal change at the various substrate temperatures. Furthermore, the variance of the grain size at various substrate temperatures is smaller for the samples on top of the off-axis substrates. 

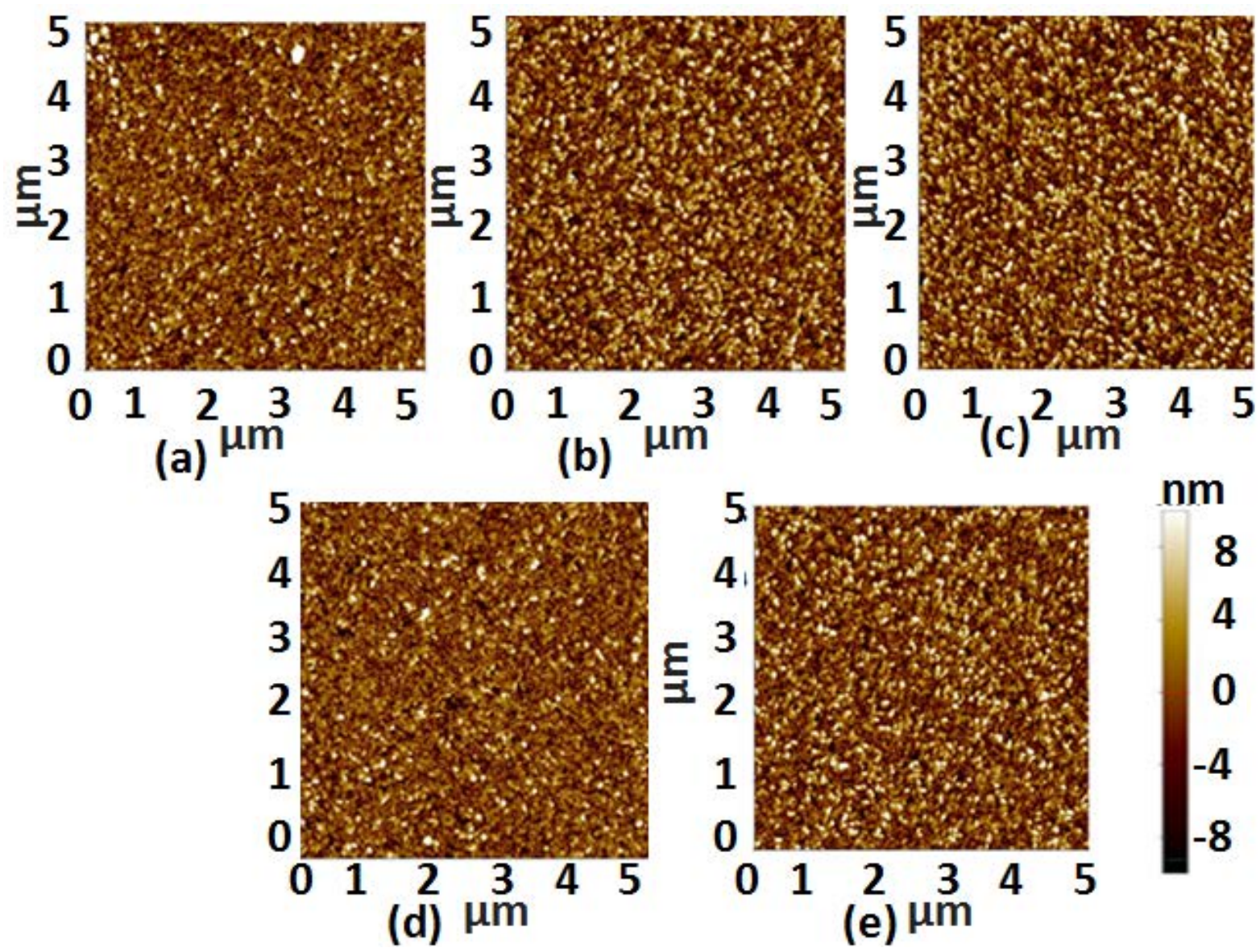

Fig. 5 AFM images of the AlN films on top of the on-axis 3C-SiC/Si substrates at various substrate temperature, (a) Sample Y1 at $250{ }^{\circ} \mathrm{C}$ (b) Sample Y2 at $300{ }^{\circ} \mathrm{C}$ (c) Sample Y3 at $350{ }^{\circ} \mathrm{C}$ (d) Sample Y4 at $400{ }^{\circ} \mathrm{C}$ (e) Sample Y5 at $450{ }^{\circ} \mathrm{C}$

The root mean square (rms) roughness of the AlN films was measured using an Atomic Force Microscopy (NX20 AFM, Park Systems, Suwon, Korea). The measurement is performed in a contact mode with a silicon cantilever (Point Probe Plus, Nanosensors, Neuchatel, Switzerland) on a $5 \mu \mathrm{m}$ by $5 \mu \mathrm{m}$ area. The XEI software (Park Systems) was used to plot the surface roughness. Figure 5 shows the AFM images of the AlN films on top of the on-axis substrates at various substrate temperatures. The data from Table 1 demonstrate that the average value and the standard deviation of the surface roughness for samples Y1 to Y5 are $3.7 \mathrm{~nm}$ and $0.27 \mathrm{~nm}$, respectively. The low value of the standard deviation indicates that 
there is no specific trend as a function of the substrate temperature. Jin et al. [10] also reported similar data for their AIN films on top of the Si (100) substrates. Their surface roughness was primarily between 2 to $3 \mathrm{~nm}$, at a much wider range of substrate temperatures i.e. 60 to $520^{\circ} \mathrm{C}$.

The AFM images of the AlN films that were deposited on top of the off-axis substrates at various substrate temperatures are shown in Figure 6. The data is recorded in Table 1. The average value of the surface roughness for samples Z1 to Z5 is $2.68 \mathrm{~nm}$, with the standard deviation of $0.2 \mathrm{~nm}$. In other words, the surface of the AlN films on top of the off-axis substrates is $27 \%$ smoother than the AlN films on top of the on-axis substrates. It is stated in the first paragraph of section 2 that the surface roughness of the on-axis 3C-SiC film is $2.386 \mathrm{~nm}$, while the surface roughness of the off-axis $3 \mathrm{C}-\mathrm{SiC}$ film is $0.93 \mathrm{~nm}$. That is, the surface of the latter is $61 \%$ smoother than the former. Based on these data, it is safe to state that the surface roughness of the substrate influences the surface roughness of the AlN film on top of it [23]. Further, the AlN films on top of the off-axis substrates have a smoother surface. However, it must be noted the differences in the surface roughness is not proportional. That is, there is the $27 \%$ difference between AlN films of both substrates, as opposed to the $61 \%$ difference between the on- and off-substrates themselves. This indicates that there are other factors that affect the surface roughness of the AlN films. This issue needs further investigation and is beyond the scope of this paper. 


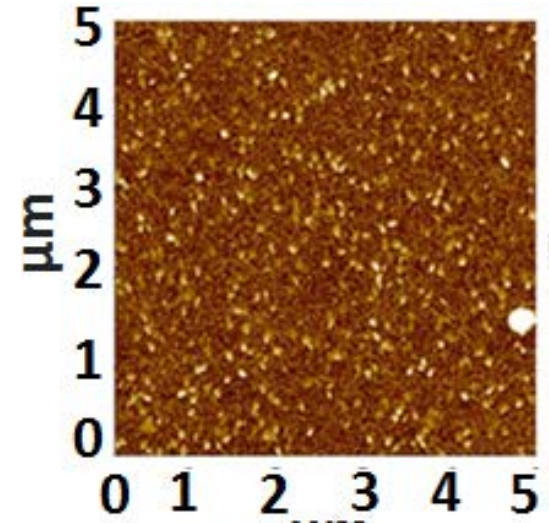

(a)

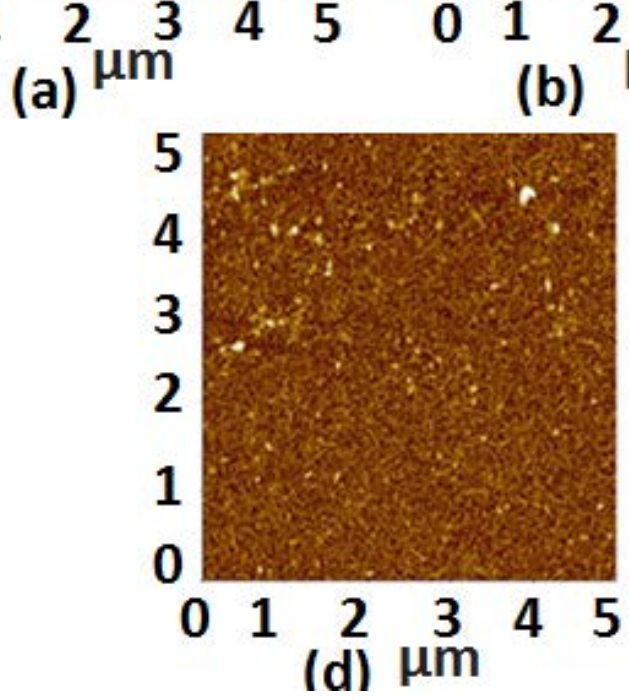

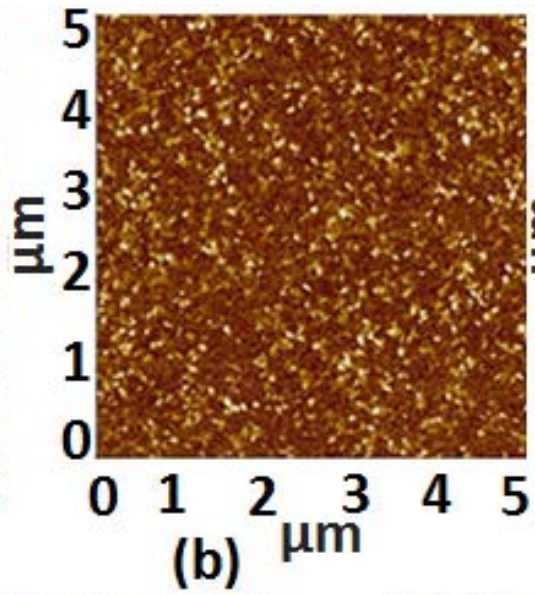
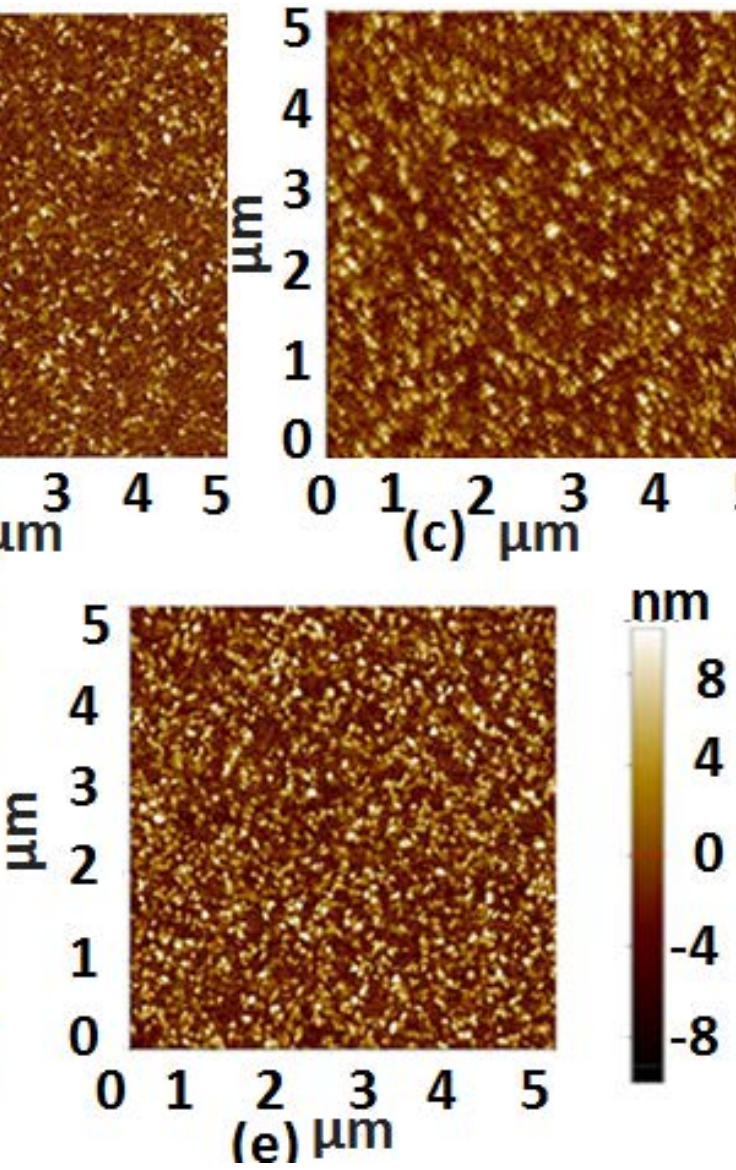

Fig. 6 AFM images of the AlN films on top of the off-axis 3C-SiC/Si substrates at various substrate temperature, (a) Sample Z1 at $250{ }^{\circ} \mathrm{C}$ (b) Sample Z2 at $300{ }^{\circ} \mathrm{C}$ (c) Sample Z3 at 350 ${ }^{\circ} \mathrm{C}$ (d) Sample Z4 at $400{ }^{\circ} \mathrm{C}$ (e) Sample Z5 at $450{ }^{\circ} \mathrm{C}$

The values of the biaxial stress were calculated for all films and are recorded in Table I. The biaxial stress $(\sigma)$ was calculated using the following equation:

$\sigma=-812.41 \times 10^{9}\left(\left(c-c_{0}\right) / c_{0}\right)$

where $c_{0}$ is the strain-free lattice parameter $\left(c_{0}=4.9795 \AA\right)$ from an AlN powdered sample [35]. The value of $c$ was extracted from the experimental data as follows: $c=2 d$, where $d=$ $\lambda / 2 * \sin \theta$ from Braggs law, $\lambda=1.5405980 \AA$ and $\theta$ is diffraction angle from the GIXRD $2 \theta$ plot. 
For the AlN films on top of the on-axis substrates, initially the bi-axial stress decreases with the increasing substrate temperature. The minimum stress is achieved at 350 ${ }^{0} \mathrm{C}$ for sample Y3. The stress increases again once the substrate temperature reaches $450{ }^{0} \mathrm{C}$ for sample Y5. This trend is consistent with the trend for the crystal quality in term of the value of the FWHM of the rocking curve. Therefore, the influence of the bi-axial stress to the crystal quality of the film is established. Finally, the average bi-axial stress value for all samples on top of the on-axis substrates is $2.82 \mathrm{GPa}$, with the standard deviation of $0.25 \mathrm{GPa}$.

We have also calculated the values of the bi-axial stress for the AlN thin films on top of the off-axis substrates. The average value for all samples is 2.39 GPa. Therefore, the offaxis substrates produced AlN thin films with lower bi-axial stress, as an indication of the better quality of their films. This trend is consistent with the lower values of their FWHM of rocking curve. Interestingly, there is no noticeable trend between the bi-axial stress of the AlN films on top of the off-axis substrate and the substrate temperature. The standard deviation for samples $\mathrm{Z} 1$ to $\mathrm{Z} 5$ is $0.47 \mathrm{GPa}$, which is higher than the standard deviation for the AlN samples on top of the on-axis substrate i.e. 0.25 GPa. At this juncture, it is worth reminding the readers again that both substrates have the same TCE difference. Further, the films that were sputtered on top of the on- and off-axis substrates were batch-fabricated. Therefore, they have the same thickness at one particular substrate temperature. Both factors majorly influenced the film's stress. Since the values are similar for the on- and off-axis substrates, the corresponding values of the bi-axial stress and its trend at various substrate temperature should be consistent. That is not so, as shown in Table 1. Therefore, further study is needed to find other influencing factors, especially for the samples on top of the offaxis substrate.

In comparison with the previously published works that either measured the residual stress or extracted the bi-axial stress of their AlN films, the values that we obtain in this 
experiment is rather high. However, several applications could make use of AlN films with such tensile stress. For example, Iborra et al. [36] reported similar range of residual stress for their sputtered AIN films and successfully developed the SAW filters.

The thicknesses of all AlN films were obtained using the spectroscopic reflectometer (Nanospec AFT 210, Nanometrics, Milpitas, CA, USA). We used the wavelength of $632 \mathrm{~nm}$ and assumed the theoretical value of 2.14 for the AlN refractive index. In order to accurately measure the reflection between the AlN film and the Si substrate without interference from the 3C-SiC buffer layer, we had to separately deposit AlN films on top of the p-type doped Si (100) wafers. These AlN/Si (100) samples were batch-sputtered with the ones that were sputtered on top of the on-axis and off-axis 3C-SiC/Si (111) substrates. The data for the thickness of the sputtered AlN films are provided in Table I. All the sputtering was carried out for $44 \mathrm{~min}$, which resulted in the film thickness ranging from 648 to $686 \mathrm{~nm}$. The average thickness is $665 \mathrm{~nm}$, with the standard deviation of $13.6 \mathrm{~nm}$. These values are identical for the samples on top of the on-axis and the off-axis substrates. The small value of the standard deviation indicates that the substrate temperature has minimal effect on the thickness of the AlN films. The deposition rate of the AlN films were calculated from the thickness of the AlN film over the deposition time, and this data is recorded in Table I. The average deposition rate is $15.04 \mathrm{~nm} / \mathrm{min}$. The closest value in the literature was reported by Jin et al. [10]. His group obtained the average deposition rate of $21 \mathrm{~nm} / \mathrm{min}$, and varied the substrate temperatures from $60^{\circ} \mathrm{C}$ to $520^{\circ} \mathrm{C}$. 


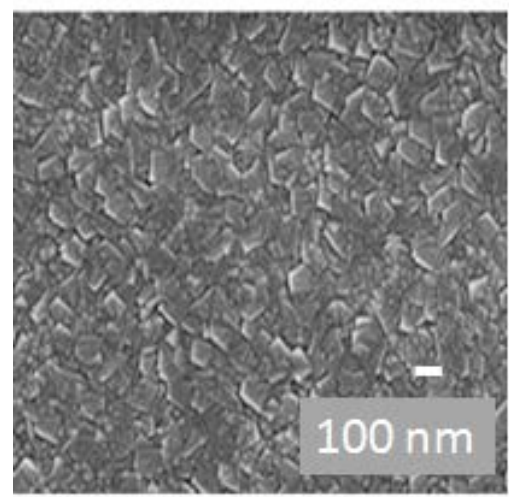

(a) Y1

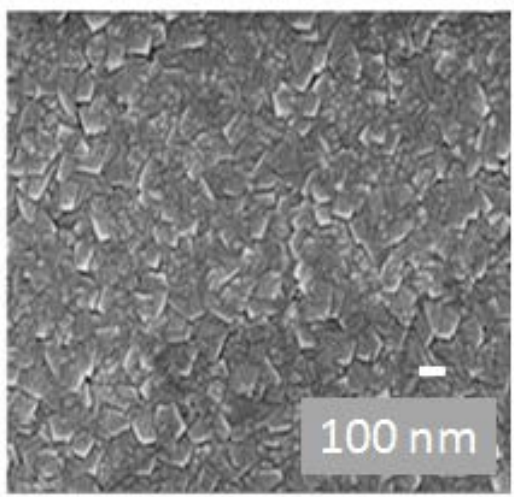

(b) Y2

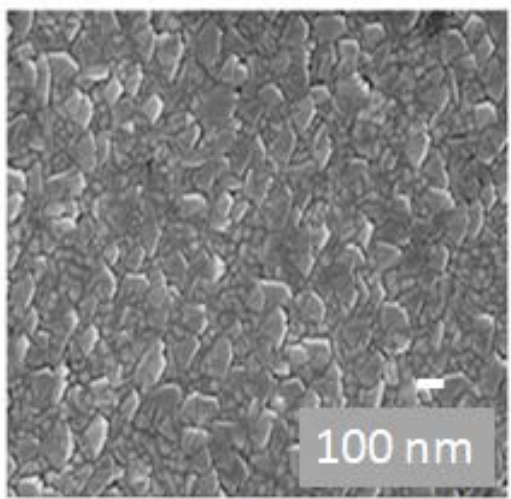

(c) $\mathrm{Y} 3$

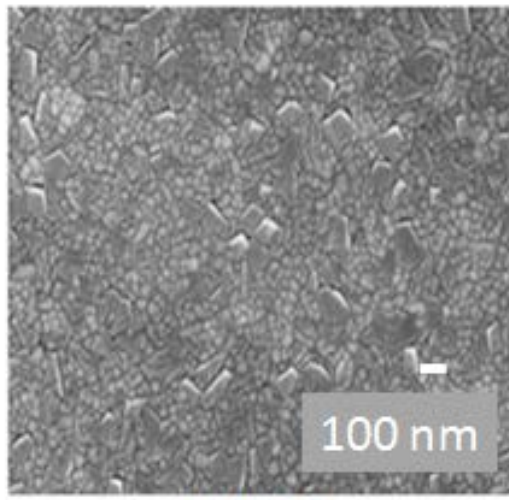

(d) Y4

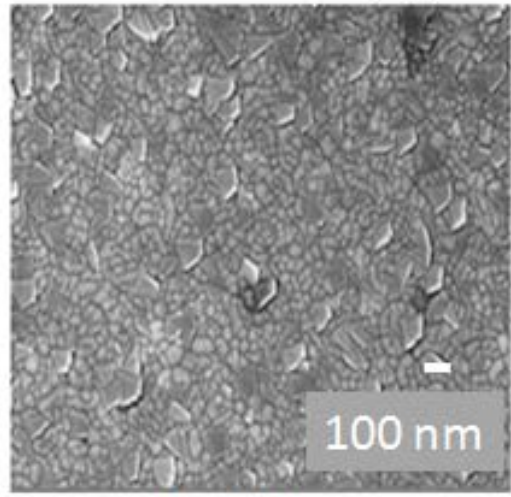

(e) Y5

Fig. 7 High resolution images of the surface of the AlN films on top of the on-axis substrates at various substrate temperatures: (a) sample $\mathrm{Y} 1$ at $250{ }^{\circ} \mathrm{C}$ (b) sample $\mathrm{Y} 2$ at $300{ }^{\circ} \mathrm{C}$ (c) sample $\mathrm{Y} 3$ at $350{ }^{\circ} \mathrm{C}$ (d) sample $\mathrm{Y} 4$ at $400{ }^{\circ} \mathrm{C}$ (e) sample $\mathrm{Y} 5$ at $450{ }^{\circ} \mathrm{C}$

Figure 7 shows the surfaces of the AlN films on top of the on-axis substrates at various substrate temperatures. These high-resolution images were taken by the Electron Beam Lithography system (Raith150 TWO, Dortmund, Germany). It is very apparent that the films have hillocks i.e. rough surface structure that is due to a high tensile stress. According to Thornton and Hoffman [37], this tensile stress is due to the low adatom mobility during the formation of the AlN film. Similar surface condition for sputtered AlN film was reported by Lee et al. in Figure 4(d) of their article [38]. Their film had the tensile stress of 0.67 GPa. We calculated the value of the bi-axial stress of our films from the shift of the diffraction peaks, 
as shown in Table 1. Since all our films possess tensile stress that is bigger than $0.67 \mathrm{GPa}$, the hillocks on their surfaces are even more visible. As Lee et al. [38] noted, the severity of the hillocks could be related to the surface roughness. The lowest value of the latter parameter (3.35 nm) is for sample Y4 at the substrate temperature of $400{ }^{\circ} \mathrm{C}$. The SEM image of Figure 7 (d) shows that the film at this particular temperature has the less number of hillocks. This enables us to perform a closer inspection on the surface of sample Y4. If we focus on the surface that is not obstructed by the hillocks, the pebble-like pattern could be observed on the grains. This indicates the typical growth of AlN (002) film.

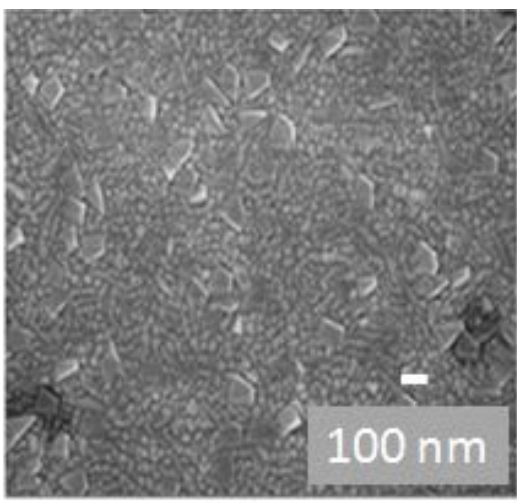

(a) Z1

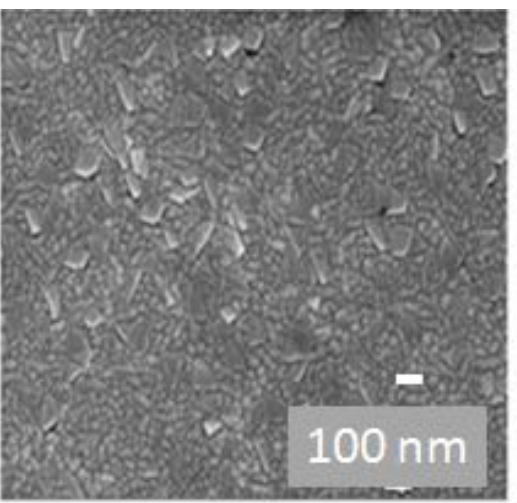

(b) Z2

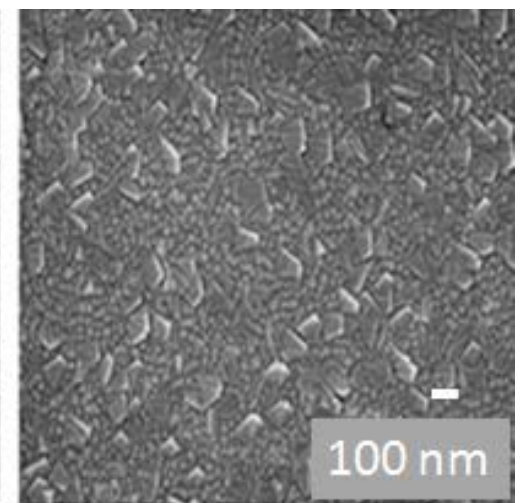

(c) Z3

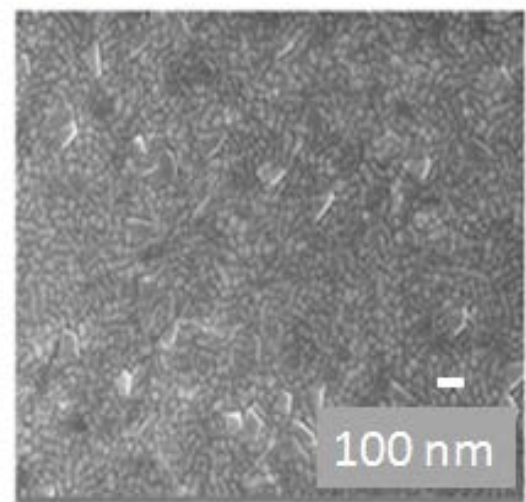

(d) Z4

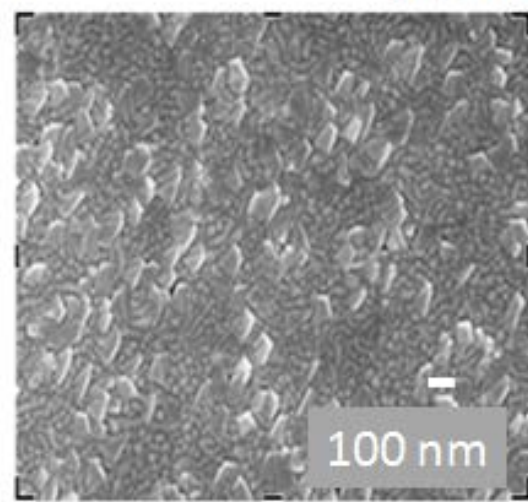

(e) $Z 5$

Fig. 8 High resolution images of the surface of the AlN films on top of the off-axis substrates at various substrate temperatures: (a) sample Z1 at $250{ }^{\circ} \mathrm{C}$ (b) sample $\mathrm{Z} 2$ at $300{ }^{\circ} \mathrm{C}$ (c) sample Z3 at $350{ }^{\circ} \mathrm{C}$ (d) sample Z4 at $400{ }^{\circ} \mathrm{C}$ (e) sample Z5 at $450{ }^{\circ} \mathrm{C}$ 
The high resolution images of the surface of the AlN films on top of the off-axis substrates at various substrate temperatures are shown in Figure 8. Similar to Figure 7, all films have hillocks that are due to the high tensile stress. However, the hillocks on the surface of sample Z1 to Z5 are less visible in comparison to the hillocks on the surfaces of samples Y1 to Y4. This observation is consistent with the lower average surface roughness for the former. If we carefully study all the images in Figure 8, the sample with the lowest number of hillocks is Z4. This observation is consistent with its lowest surface roughness of $2.38 \mathrm{~nm}$. The absences of hillocks in many places on Figure 8(d) enable us to see the pebble-like grain pattern on the surface.

We also took the cross-sectional images using the same Electron Beam Lithography system. This was done to provide evidence of the formation of the c-axis AlN structure. Sample Z3 and Y4 were randomly selected for this purpose. Their images were shown in Figure 9 (a) and 9 (b). Three major observations are noted. First, the images clearly enable the readers to separate the Si substrate, the 3C-SiC layer, the AlN layer and the hillocks above the AlN film. It is apparent that the hillocks on top of sample Z3 is less visible. Also, The 3C-SiC layer for that sample is tilted towards the (110) plane. Second, the high resolution images offer an alternative method to find the thickness of the 3C-SiC and AlN films based. These values are quite close to the ones that were obtained using the spectroscopic reflectometer. This indicates the accuracy of the reflectometer, even though it used the theoretical value of the AIN refractive index to calculate the film's thickness. Third, both images provide evidence of the columnar growth on the majority of the films. However, the growth of other planes could also be observed. This last observation confirmed the deposition of the c-axis AlN structures. 


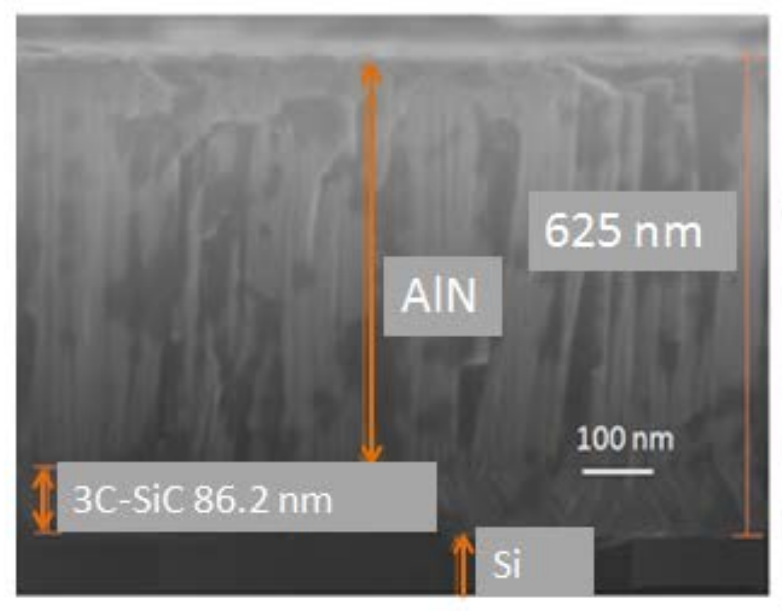

(a)

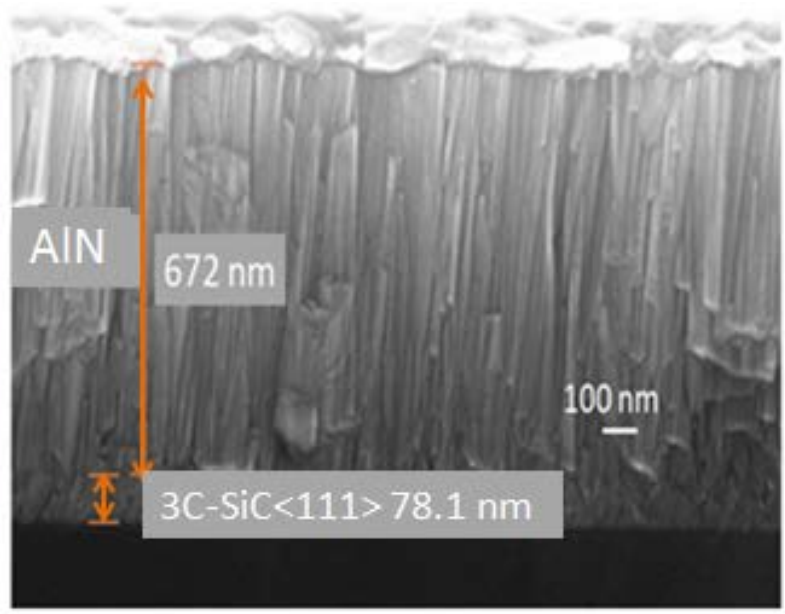

(b)

Fig. 9 Cross sectional images of AlN/3C-SiC/Si compound structure: (a) sample Z3 on top of the off-axis substrate (b) sample Y4 on top of the on-axis substrate

Sample Z3 was further characterized using the C-V measurement to extract its piezoelectric coefficient $\mathrm{d}_{33}$. The details of this measurement setup have been explained in section 2 of this manuscript. The capacitance value $\left(\mathrm{C}_{0}\right)$ is measured to be $85.75 \mathrm{pF}$ at the DC voltage of $0 \mathrm{~V}$ and the frequency of $1 \mathrm{kHz}$. We calculate the value of $\mathrm{d}_{33}$ based on Equation 2 [27]. The change in vertical extension $\Delta$ d (thickness) was calculated from Equation $5 . \mathrm{C}_{\mathrm{r}}$ is the ratio of the capacitance at certain bias voltage $\left(C_{v}\right)$ over $C_{0}$. The values of $C_{r}$ are 0.997 and 1.002 at the biasing of $+25 \mathrm{~V}$ and $-25 \mathrm{~V}$, respectively. Since the value of $d$ (thickness of the film) is equal to $657 \mathrm{~nm}$ from Table 1 , we obtained the $\mathrm{d}_{33}$ value of $47 \mathrm{pm} / \mathrm{V}$ for sample Z3. It should be noted that our extracted value is approximately 10 times higher than the $d_{33}$ value of bulk AlN ( 5.31 pm/V) [39].

We searched the literature to find the reason for this discrepancy. One group at University of Twente i.e. van Hemert et al. [40] reported similar value of $d_{33}$ for their AlN films i.e. $50 \mathrm{pm} / \mathrm{V}$ using the same $\mathrm{C}-\mathrm{V}$ setup as ours. Another group at Tyndall National Institute i.e. Jackson et al. [41] investigated further by comparing three different 
measurement techniques to extract the piezoelectric coefficient of their AlN film. They reported a $\mathrm{d}_{33}$ value of $2 \mathrm{pm} / \mathrm{V}$ using laser doopler vibrometer, $4.8 \mathrm{pm} / \mathrm{V}$ using piezoelectric force microscopy and $51.3 \mathrm{pm} / \mathrm{V}$ using the $\mathrm{C}-\mathrm{V}$ measurement. A clear trend can be observed by three different groups that measured the $\mathrm{d}_{33}$ parameter using the $\mathrm{C}-\mathrm{V}$ measurement. That is, this specific measurement churned out the $\mathrm{d}_{33}$ value that is about 10 times the expected result. Further works need to be performed to identify the reason for the large disparity between this technique and others in term of measuring the $d_{33}$ parameter of AlN thin film. It should be stated that the $\mathrm{C}-\mathrm{V}$ measurement is the simplest among the three, and thus making is the most attractive choice for researchers.

\section{Conclusion:}

We have DC sputtered AlN thin films on top of on- and off-axis 3C-SiC (111)/Si (111) substrates at various substrate temperatures. We conclude the followings. First, all samples produce the polycrystalline AlN films with major peak along the (002) plane, as evidenced by the GIXRD scan, the rocking curve measurement and the cross-sectional images. Second, the increasing substrate temperature improves the crystal quality of the AlN films on both substrates. However, it has minimal impact on the surface roughness and deposition rate. Third, the AlN films on top of the off-axis substrates have better crystal quality, lower surface roughness and lower bi-axial stress, in comparison to the ones on top of on-axis substrates. The average FWHM of rocking curve values, the average surface roughness values and the average bi-axial stress values for the films on top of the on- and offaxis substrates are $3.3^{0}, 3.7 \mathrm{~nm}, 2.82 \mathrm{GPa}, 2.4^{0}, 2.68 \mathrm{~nm}$ and $2.39 \mathrm{GPa}$, respectively. Fourth, all the films possess a high value of bi-axial stress (tensile), which caused the formation of hillocks on the surface of all films. The high value of tensile stress limits the potential applications to SAW devices. Fifth, our future works will be focused on reducing the value of 
the residual stress by varying the substrate bias. This is a well-known method to control the film's stress. The biasing will also improve the crystal quality of the c-axis AlN by providing low energy ion bombardment to precisely control the surface energy.

\section{Acknowledgments}

This work is supported by Queensland Micro- and Nanotechnology Centre (QMNC) and Griffith School of Engineering. This work was performed in part at the Queensland node of the Australian National Fabrication Facility, a company established under the National Collaborative Research Infrastructure Strategy to provide nano and microfabrication facilities for Australia's researchers. The authors would like to acknowledge Mr. Zailan Mohd Yusof of The National University of Malaysia (Bangi) for the grazing-incident XRD measurements.

\section{References:}

[1] J. Ruffner, P. Clem, B. Tuttle, D. Dimos, D. Gonzales, Thin Solid Films 354, 256 (1999).

[2] A. Claudel, Y. Chowanek, E. Blanquet, D. Chaussende, R. Boichot, A. Crisci, G. Berthomé, H. Mank, S. Luca, D. Pique, Phys. Status Solidi C. 8, 2019 (2011).

[3] D. Isarakorn, A. Sambri, P. Janphuang, D. Briand, S. Gariglio, J. Triscone, F. Guy, J. Reiner, C. Ahn, N. de Rooij, J. Micromech. Microeng. 20, 055008 (2010).

[4] V. Cimalla, J. Pezoldt, O. Ambacher, J. Phys. D. Appl. Phys. 40, 6386 (2007).

[5] C. Zuo, N. Sinha, J. Van der Spiegel, G. Piazza, J. Microelectromech. Syst. 19, 570 (2010).

[6] K.H. Chiu, J.H. Chen, H.R. Chen, R.S. Huang, Thin Solid Films 515, 4819 (2007). 
[7] X.P. Kuang, H.Y. Zhang, G.G. Wang, L. Cui, C. Zhu, L. Jin, R. Sun, J.C. Han, Superlattices. Microstruct. 52, 931 (2012).

[8] G. Iriarte, J. Rodriguez, F. Calle, Mater. Res. Bull. 45, 1039 (2010).

[9] M. Benetti, D. Cannata, F. Di Pietrantonio, E. Verona, A. Generosi, B. Paci, V.R. Albertini, Thin Solid Films 497, 304 (2006).

[10] H. Jin, B. Feng, S. Dong, C. Zhou, J. Zhou, Y. Yang, T. Ren, J. Luo, D. Wang, J. Electron. Mater. 41, 1948 (2012).

[11] W.J. Liu, S.J. Wu, C.M. Chen, Y.C. Lai, C.H. Chuang, J. Cryst. Growth 276, 525 (2005).

[12] H.C. Barshilia, B. Deepthi, K. Rajam, Thin Solid Films 516, 4168 (2008).

[13] J. Kar, G. Bose, S. Tuli, Curr. Appl. Phys. 6, 873 (2006).

[14] J. Wang, Q. Zhang, G.F. Yang, C.J. Yao, Y.J. Li, R. Sun, J.L. Zhao, S.M. Gao, J. Mat. Sci.: Mater. Electron. 27, 3026 (2016).

[15] J. Yang, X. Jiao, R. Zhang, H. Zhong, Y. Shi, B. Du, J. Electron. Mater. 43, 369 (2014).

[16] H. Watanabe, N. Yamada, M. Okaji, Int. J. Thermophys. 25, 221 (2004).

[17] A. Iqbal, G. Walker, L. Hold, A. Fernandes, A. Iacopi, F. Mohd-Yasin, J. Vac. Sci. Tech. B 35, 06GH01 (2017).

[18] H.S. Kong, B. Jiang, J.T. Glass, G. Rozgonyi, K. More, J. Appl. Phys. 63, 2645 (1988).

[19] J. Powell, L. Matus, M. Kuczmarski, C.M. Chorey, T. Cheng, P. Pirouz, Appl. Phys. Lett. 51, 823 (1987). 
[20] L. Wang, G. Walker, J. Chai, A. Iacopi, A. Fernandes, S. Dimitrijev, Sci. Rep. 5, 15423 (2015).

[21] A. Severino, R. Anzalone, C. Bongiorno, M. Italia, G. Abbondanza, M. Camarda, L. Perdicaro, G. Condorelli, M. Mauceri, F. La Via, Mater. Sci. Forum 149, 149 (2009).

[22] A. Severino, C. Bongiorno, N. Piluso, M. Italia, M. Camarda, M. Mauceri, G. Condorelli, M. Di Stefano, B. Cafra, A. La Magna, Thin Solid Films 518, S165 (2010).

[23] A. Artieda, M. Barbieri, C.S. Sandu, P. Muralt, J. Appl. Phys. 105, 024504 (2009).

[24] C.M. Lin, W.C. Lien, V.V. Felmetsger, M.A. Hopcroft, D.G. Senesky, A.P. Pisano, Appl. Phys. Lett. 97, 141907 (2010).

[25] A. Iqbal, G. Walker, A. Iacopi, F. Mohd-Yasin, J. Cryst. Growth 440, 76 (2016).

[26] A. Ababneh, M. Alsumady, H. Seidel, T. Manzaneque, J. Hernando-García, J. SánchezRojas, A. Bittner, U. Schmid, Appl. Surf. Sci. 259, 59 (2012).

[27] M. Al Ahmad, R. Plana, IEEE Microw. Wirel. Compon. Lett. 19, 140 (2009).

[28] N.N. Rogacheva, The theory of piezoelectric shells and plates, $1^{\text {st }}$ edn. (CRC Press, Boca Raton, 1994).

[29] S. Khan, M. Shahid, A. Mahmood, A. Shah, I. Ahmed, M. Mehmood, U. Aziz, Q. Raza, M. Alam, Prog. Nat. Sci: Mater. Int. 25, 282 (2015).

[30] O.M. Lemine, Superlattices. Microstruct. 45, 576 (2009)

[31] F. Medjani, R. Sanjines, G. Allidi, A. Karimi, Thin Solid Films 515, 260 (2006).

[32] S. Tungasmita, J. Birch, P. Persson, K. Jarrendahl, L. Hultman, , Mater. Sci. Eng.: B, 172, 253 (2010). 
[33] T. Kumada, M. Ohtsuka, H. Fukuyama, AIP Advances 5, 017136 (2015).

[34] D. Song, P. Widenborg, W. Chin, A.G. Aberle, Sol. Energy. Mater. Sol. Cells 73, 1 (2002).

[35] W.T. Lim, B.K. Son, D.H. Kang, C.H. Lee Thin Solid Films 382, 56 (2001)

[36] E. Iborra, M. Clement, J. Sangrador, A. Sans-Hervas, L. Vergara, M. Aguilar, IEEE IEEE Tran. Ultrason. Ferroelectr. Freq. Control. 51, 352 (2004)

[37] J.A. Thornton, D.W. Hoffman, Thin Solid Films 171, 5 (1989).

[38] S.H. Lee, K.H. Yoon, D.S. Cheong, J.K. Lee, Thin Solid Films 435, 193 (2003).

[39] K. Tonisch, V. Cimalla, C. Foerster, H. Romanus, O. Ambacher, D. Dontsov, Sens. Actuators A. Phys. 132, 658 (2006).

[40] T. van Hemert, D. Sarakiotis, S. Jose, R. Hueting and J. Schmitz, in International Conference on Microelectronic Test Structures (2011), pp. 69-73.

[41] N. Jackson, O.Z. Olszewski, L. Keeney, A. Blake and A. Mathewson, in International Conference on Microelectronic Test Structures (2015), pp. 193-197. 